\title{
Aminoflavone Prodrug AFP464
}

National Cancer Institute

\section{Source}

National Cancer Institute. Aminoflavone Prodrug AFP464. NCI Thesaurus. Code C48370.

A synthetic lysyl prodrug of the amino-substituted flavone derivate aminoflavone with antiproliferative and antineoplastic activities. AFP464 is rapidly converted to aminoflavone in plasma. Aminoflavone activates the aryl hydrocarbon receptor (AhR) signaling pathway leading to an increase in cytochrome P450 1A1 (CYP1A1) and cytochrome P450 1A2 (CYP1A2) expression and, to a lesser extent, an increase in cytochrome P450 1B1 (CYP1B1) expression. Subsequently, aminoflavone is metabolized to toxic metabolites by the cytochromome P450 enzymes that it induces; these toxic metabolites covalently bind to DNA, resulting in the phosphorylation of p53, the induction of the p53 downstream target p21Waf1/Cip1, and apoptosis. Pulmonary toxicity may be dose-limiting. 